\title{
ENTRELAÇANDO PAISAGENS: CARNAVAL E MEMÓRIA
}

\author{
Maria Luiza Berwanger da Silva
}

RESUMO: Le symbolisme de la dédicasse vu comme geste qui cache, sous l 'amitié intellectuelle (telle que la conçoivent Jacques Derrida et Maurice Blanchot), le profond dialogue intertextuel, se propose à examiner dans cette étude, la rentabilité théorique - critique de l 'image du "carnaval " pour la reconfiguration du lyrisme brésilien. Ancrée dans la réflexion de certains critiques latino-américains, cette image permettra le double mouvement textuel d'enregistrement et de transgression de l 'imaginaire national, permettant l 'insertion de la subjectiveté brésilienne dans le grand espace latino-américain. Ces poésies échangées entre Mário de Andrade et Manuel Bandeira figurées donc commel 'une des répresentation exemplaires de projet commun à ces deux poètes brésiliens de décanter le lyrisme brésilien et que la dédicasse, légitimée dans les lettres, traduit singulièrement.

PALAVRAS-CHAVE: amizade, intextualidade, carnaval, lirismo decantado, simbolismo da dedicatória , paisagem, inscrição e transgressão textual.

"A música não sabe nem conseguirá jamais saber quais os seus limiares expressivos."

(Mário de Andrade. O Baile das Quatro Artes, 1941)

"A imagem do corpo como peregrinação nos devolve a imagem do corpo como escritura" (O.

PAZ. El Pensamiento en Blanco)

"Este, em traço esquemático, o curso hispano-americano do processo."

Haroldo de Campos. O Arco-Íris Branco

"Manuel Bandeira,

... Sai da leitura com a convicção profunda de que o teu livro (Carnaval) foi um clarim de era nova, cantando já sem incertezas nem rouquidões."

Mário de Andrade (São Paulo, 06.02.1922)

Maria Luiza Berwanger da Silva é professora do Instituto de Letras da UFRGS. 
Vasta e contínua, a troca de correspondência entre Mário de Andrade e Manuel Bandeira revitaliza-se na dedicatória de Carnaval Carioca (1923) ao conjunto de poemas Carnaval (1908-1910) do poeta de As Cinzas das Horas. Gera um certo movimento textual que oculta, sob o gesto de homenagem, o redesenhar da paisagem poética brasileira. Se o entrelaçamento da carta à dedicatória projeta a teoria francesa sobre as relações de amizade, captada dos Essais de Montaigne, o fio primeiro desse pacto de cumplicidade encontra a modulação definitiva em Politiques de l'Amitié (1994) de Jacques Derrida:

"Si l'amitié projette son espoir au-delà de la vie,...

c'est parce que l'ami est sa 'propre image idéale',

son autre soi-même, le même que soi en mieux."

Representação exemplar do imaginário brasileiro que fixa na produção de vanguarda o lugar e o ato da poesia, o diálogo a meio tom tecido pela dedicatória de Carnaval Carioca de Mário de Andrade a Bandeira faz-se registro desse rito de travestimento, onde a máscara, a alegria e a memória articulam o artesanato da linguagem poética. Amizade e homenagem, pois, como expressão do olhar que perscruta transparências, traduz ângulos, e que, ao fazê-lo, incorpora novas associações de imagens e de procedimentos ao território da poesia brasileira.

Crítico lúcido e atento à subversão poético-crítica processada pelo carnaval, dirá Emir Rodríguez Monegal:

"En el concepto de Carnaval, América Latina ha encontrado un instrumento útil para alcanzar la integración cultural que está en el futuro y para verla no como sumisión a los modelos occidentales, no como mera corrupción de algún original sagrado, sino como parodia de un texto cultural que en sí mesmo ya contenia la semilla de sus propias metamorfosis" (MONEGAL, 1979, p.408),

o que corresponde a inserir a poesia brasileira na produção latino-americana de vanguarda, com base no projeto de reinvenção textual: a poesia capta do ritmo carnavalesco o resíduo da voz que, musical, traça e retraça a fisionomia lírica. Daí, talvez, a modulação do Carnaval de Bandeira pela marca da negatividade, insinuando, paradoxalmente, a reescritura do mito.

À nostalgia dos versos:

"Eu quis um dia, como Schumann, compor

Um carnaval todo subjetivo:

Um carnaval em que o só motivo

fosse o meu próprio ser interior...

Quando o acabei, - a diferença que havia!

O de Schumann é um poema cheio de amor,

- O meu carnaval sem nenhuma alegria."

(BANDEIRA, 1996, p.178)

somam-se a constelação de figuras carnavalescas (Pierrot, Colombina, Arlequim, entre outras) e a multiplicidade de formas musicais (rimancete, madrigal, rondó e bala- 
da, por exemplo). Visualizados como expressão do desejo de estabelecer uma poética da relação, onde o gesto de reinventar o Outro autorizaria, paralelamente, o deixar transformar-se pelo Outro, esses versos apontam para o espaço poético a ser produzido entre a cópia e a transformação da matriz européia. Distanciamento de Schumann e travestimento singular e brasileiro dos tipos mascarados condensam-se no fundo do Pierrot triste tentando "romper na treva a esfera dos astros" (Idem, p.161), paralela ao simbolismo das "velas que fogem como garças longínquas no ar" (Idem). Na leitura do carnaval bandeirano, inscrever na página a modulação carnavalesca que se propaga sem deixar marcas equivale a contrariar o projeto da composição poética que busca fixar a certeza da subjetividade recriada no traço e na rasura. Sob, pois, os versos finais de Sonho de uma Terça-Feira Gorda,

$$
\text { ". }
$$

Nós caminhávamos de mãos dadas com solenidade,

$\mathrm{O}$ ar lúgubre, negros, negros...

Mas dentro em nós era tudo claro e luminoso!

Nem a alegria estava ali, fora de nós.

A alegria estava em nós.

Era dentro de nós que estava a alegria,

- A profunda, a silenciosa alegria..." (Idem, p.178),

o resgate da alegria já antecipa a escritura do poema Os Sapos, como produção do espaço múltiplo e transgressivo. Torpe, dissonante, o coaxar dos sapos traduz o jogo que o carnaval concede ao eu lírico. No avesso do rito da festa, Os Sapos fazem-se superação da dubiedade amorosa de Pierrot, do mesmo modo que ocultam, sob a máscara da oscilação, o olhar que percebe e aclimata a diversidade e a mescla.

Mário de Andrade parece ter compreendido com muita clareza o desejo bandeirano do lirismo multifacetado e que $O$ s Sapos insinuam de modo exemplar. Se a dedicatória de Carnaval Carioca a Manuel Bandeira reverte a recepção crítica desfavorável da Revista do Brasil, principalmente a de Monteiro Lobato, transformando-a em aclamação fervorosa por Guilherme de Almeida ${ }^{1}$, no poema de Mário de Andrade, o gesto de cumplicidade, que harmoniza diferenças regionais brasileiras e identidades outras, ressalta a dupla função da escritura poética enquanto registro e disseminação do imaginário local. Versos como:

"Aleluia!

Louvemos $\mathrm{O}$ que permanece através das festanças virtuosas e dos gozos ilegítimos!

Louvêmo-Lo (o Criador) sempre e sobre tudo!

Louvêmo-Lo com todos os instrumentos e todos os ritmos." (ANDRADE, 1987, p.169)

e os fragmentos finais:

"O poeta se debruça no parapeito de granito.

A rodelinha de confeti cai do chapéu dele,

Vai saracotear ainda na sombra mole das ondas." (Idem, p.173)

${ }^{1}$ Fato relatado por Manuel Bandeira em Itinerário de Pasárgada. In: Poesia Completa e Prosa, p.58. 
expressam a profunda correlação da memória residual com o desejo de permanência. Assim, Mário de Andrade celebra Bandeira não só agregando o movimento poético da condensação ao da expansão, mas, também, redesenhando lucidamente a cartografia da poesia brasileira: centra-a sobre uma certa singularidade da memória com que compõe a paisagem poética.

Nos versos finais de Carnaval Carioca,

"Então o poeta vai deitar

Lentamente se acalma no país das lembranças

A invasão furiosa das sensações.

O poeta sente-se mais seu.

E puro pelo contacto de si mesmo

Descansa o rosto sobre a mão que escreverá.

A barulhada matinal de Guanabara...

É a cantiga-de-berço.

E o poeta dorme.

O poeta dorme sem necessidade de sonhar." (ANDRADE, 1987, p.173),

o simbolismo do sonho lúcido sela a intermediação que a memória confere à teorização da escritura poética; transparece no pensamento-síntese de Alfredo Bosi em A Parábola das Vanguardas Latino-Americanas, onde diz:

"A poesia bebe no poço da memória e da visão, mas o poeta modula a sua frase na pauta surpreendente do imaginário para onde confluem as percepções da vigília cotidiana e os sonhos de um vivido sem margens precisas. Para compor a verdade da poesia (e esta é a lição de uma vanguarda que vem dos pré-românticos), entram com iguais direitos o real, o irreal e essa zona móvel entre o real e o irreal que se chama o possível" (In: SCHWARTZ, 1995, p.22).

Imagem residual da lembrança e, pois, voz transgressiva do poema, o sonho assim configurado articula o contato da poesia brasileira com outros sistemas poéticos latino-americanos.

Em Carnaval Carioca, o entrelaçamento da prática à teoria do poema, afora a preocupação vanguardista com a consciência do versejar lúcido, afora a prática de reinvenção do real, afora a liberação da forma, incide na plenitude da poesia como arquivo inapagável do projeto vanguardista de diluir as fronteiras textuais.

"Confluência continental" para Hugo Verani², "estilo transnacional" para Saúl Yurkievich (p.92) e "tapeçaria de deliberado desenho transregional" para José Paulo Paes (p.117), essa busca de ruptura dos limiares encontra o fio de origem na voz antecipadora de Octavio Paz, onde diz:

"La modernidad antimoderna de nuestra poesia ... es una verdadera transgresión. Pero una transgresión casi siempre involuntaria y que aparece sin

${ }^{2}$ Cf. VERANI, 1995, p.82. Tanto no estudo introdutório a Las Vanguardias Literárias en HispanoAmérica (1990), quanto no ensaio Estratégias de la Vanguardia (1995), Hugo Verani exclui o estudo sobre o Modernismo Brasileiro, contudo tal exclusão não impede o diálogo com os demais sistemas literários examinados. 
que el poeta se lo proponga... no es un agregado ni un elemento postizo sino la manera propia de ser de la poesia en la edad moderna" (PAZ, p.113).

No contraponto da transgressão, a memória rasurada resiste à passagem, completando o adensamento do imaginário na aproximação a outras comunidades literárias. O contato não desgasta, sorve do gesto de homenagem o percurso da disseminação poética; aponta a função que Bandeira exercerá para o sistema literário brasileiro: "poeta desconstelizador/reconstelizador" (1970, p.99-105), dirá Haroldo de Campos, em síntese exemplar da imagem do poeta de Pasárgada como reservatório inesgotável de idéias de que se nutre a lírica brasileira. Homenagear Bandeira significa portanto não só subverter a figuração mítica do carnaval, sobrepondo-lhe ao rito da passagem a nuança da permanência, mas, sobretudo, situar, na dispersão (intencional e voluntária) do Carnaval bandeirano, o gesto matricial, o grão fundador da poética dissonante e lúcida, já insinuada em Os Sapos como imagem da escritura transgressiva.

Se ao prazer da distância em Bandeira, Mário incorpora o prazer do enraizamento, do resíduo da memória em constante circulação, a "aclimatação" da Alteridade, na abrangência do verso "Geografia! Oh liberdade! Pagodeira grossa", em que se abrigam "Isoldas de pijamas bem franceses, alsacianas, portuguesas, holandesas... " não congela a irradiação do sentimento lírico na obsessão do nacional: o movimento de reordenação da realidade brasileira, com base no carnaval em mito que resiste à passagem do tempo, concede à poesia a expansão das fronteiras textuais.

De certa forma, na transparência dessa voz transgressiva, a fisionomia de uma literatura latino-americana como todo multifacetado, mas coeso, legitima a rentabilidade poética do carnaval emergente do texto de homenagem. Dança, cor, ritmo resgatam a subversão desse rito imemorial, do mesmo modo que relêem a questão identitária incidindo na formação das comunidades textuais compartilhadas.

Projeto idêntico já se encontra no poeta Jules Supervielle cuja dupla pertença cultural (uruguaia e francesa) expressa o desejo de congregar a diversidade poética, principalmente nos versos-síntese de Oublieuse Mémoire:

"Poètes des deux rivages,

Nous qui buvons nuit et jour à la fraîche source du monde

Et qui sommes familiers du pur compas des étoiles

Traçons ensemble un arc-en-ciel avec ses couleurs scrupuleuses."

(SUPERVIELLE, 1996, p.520-521).

Mas é no modernista Oswald de Andrade que a questão das “comunidades solidárias" mais se faz antecipar, considerando-se o ano de 1923, quando em pleno fervor modernista de nacionalismo ferrenho, profere a conferência na Sorbonne (Paris), L'Effort Culturel du Brésil Contemporain, onde já visualizava a Literatura Latino-Americana como "oeuvre commune de la latinité" (ANDRADE, 1923, p.197-207).

Insinuar a composição da paisagem transgressiva, em meio ao afã localista, 
correspondia, de certo modo, a legitimar o simbolismo do carnaval como mito que, ao mesmo tempo, reinventa e transgride o imaginário brasileiro. Sob a leveza da festa, acumula fragmentos, faz-se disponibilidade polissêmica essencial para a constituição da identidade poética brasileira na travessia e na busca de limites textuais móveis, intermediada pelo canto poético.

Voz que resgata o localismo e voz lírica que relê a paisagem poética pelo ângulo da impregnação de espaços outros, o gesto de amizade expresso pela escritura de Carnaval Carioca deixa emergir o esboço de corpo inteiro da poesia brasileira. Nele, resgate e releitura recolhem da modulação transgressiva do carnaval o grão da voz que fica e que expande o pacto de amizade inaugurado por Mário de Andrade a Manuel Bandeira. Se a inscrição definitiva dessa voz residual em A Falta que ama (1968) de Carlos Drummond de Andrade sela o rito de homenagem, em:

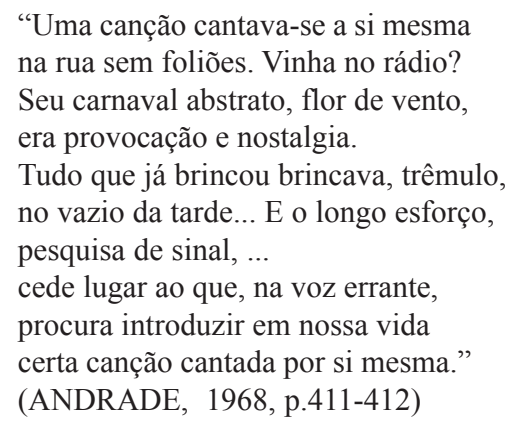

os versos do poeta chileno Vicente Huidobro, figura-síntese vanguardista, como que projetam a confluência da paisagem poética latino-americana, onde diz:

"Siglos, siglos...

Siglos que se balancean en mi canto

Que agonizan en mi voz

Porque mi voz es sólo canto y sólo puede salir en canto."

(HUIDOBRO apud MIGNOLO, 1982, p.135)

Carnaval, pois, como voz que, ao pontuar comunidades de amizade e ao intermediar a passagem da poesia brasileira à latino-americana, agrega à antecipação crítica da carta de Mário de Andrade a Manuel Bandeira, citada inicialmente (àquela "convicção profunda de um clarim de era nova, cantando já sem incertezas nem rouquidões"), o pontilhado de novos caminhos, memórias que o carnaval concede à Literatura Brasileira entre o real e o possível.

\section{BIBLIOGRAFIA}

ANDRADE, Carlos Drummond de. A Voz. In: A Falta que ama. Nova Reunião, 1968. . Nova Reunião. Rio de Janeiro, José Olympio, 1987.

ANDRADE, Mário. Poesias Completas. São Paulo, Itatiaia, 1987. 
Cartas a Manuel Bandeira. Rio de Janeiro, Simões, 1958.

ANDRADE, Oswald. L'Effort Intellectuel du Brésil Contemporain. Revue de l'Amérique Latine, $2^{\text {ème }}$ année, n.19, p.197-207, 1923.

BANDEIRA, Manuel. Poesia Completa e Prosa. Rio de Janeiro, Aguilar, 1996.

CAMPOS, Haroldo. Bandeira, o desconstelizador. In: Metalinguagem. Rio de Janeiro, Vozes, 1970.

DERRIDA, Jacques. Politiques de l'Amitié. Paris, Galilée, 1994.

JOSEF, Bella. Modernismo Brasileiro: vanguarda, carnavalização e modernidade. Revista Iberoamericana, n.118-119, p.103-120, enero-junio 1982.

MIGNOLO, Walter. El Poeta en la Lírica de Vanguardia. Revista Iberoamericana, n.118-119, p.131-148, enero-junio 1982.

MONEGAL, Emir Rodríguez. Carnaval/Antropofagia/Paródia. Revista Iberoamericana, p.401-412, julio-diciembre 1979.

PAES , Jose Paulo . A Ruptura Vanguardista :as grandes obras . In :PIZARRO, Ana ( Org. ) America Latina :Palavra, Literatura e Cultura . Sao Paulo, Memorial, Campinas ,v.III, p 98,1995.

PIZARRO, Ana (Org.). América Latina: Palavra, Literatura e Cultura. São Paulo, Memorial, Campinas, Unicamp, v.III,1995.

SCHWARTZ, Jorge. Vanguardas Latino-Americanas (Polêmicas, Manifestos e Textos Críticos). São Paulo, Edusp, Iluminuras, FAPESP, 1995.

SUPERVIELLE, Jules. Oublieuse Mémoire. In: Oeuvres Poétiques Complètes. Paris, Gallimard, 1996.

VERANI, Hugo . Estrategias de la vanguardia .In : PIZARRO, Ana (Org.) América Latina :Palavra, Literatura e Cultura . São Paulo,Unicamp,1995. p.75 a 88.

YURKIEVICH, Saúl. Los Signos Vanguardistas: el registro de la modernidad. In: PIZARRO, Ana (Org.) América Latina: palavra, literatura e cultura. São Paulo, Unicamp,1995. p.89 a 97. 